\title{
Anticancer potential of Tinospora cordifolia and arabinogalactan against benzo(a)pyrene induced pulmonary tumorigenesis: a study in relevance to various biomarkers
}

\author{
$\operatorname{Vandana~Mohan~}^{\mathbb{D}}$, Ashwani Koul* $^{\mathbb{D}}$ \\ Department of Biophysics, Basic Medical Science Block II, South campus, Panjab University, Chandigarh, India
}

\section{AR T I C L E IN F O}

Article Type:

Original Article

\section{Article History:}

Received: 10 January 2018

Accepted: 20 June 2018

\section{Keywords:}

Arabinogalactan

Benzo(a)pyrene

Lactate dehydrogenase

Medicinal plant

Tinospora cordifolia

\begin{abstract}
A B S T R A C T
Introduction: Aqueous Tinospora cordifolia stem extract (Aq.Tc) and arabinogalactan (AG), its bioactive polysaccharide, which are antioxidant remedies were evaluated on pulmonary cancer and associated tumor markers.

Methods: Mice were randomly segregated into 6 groups. Group I: animals served as control. Group II: animals which were administered Aq.Tc extract $(200 \mathrm{mg} / \mathrm{kg}$, orally), thrice a week. Group III: animals which received AG $(7.5 \mathrm{mg} / \mathrm{kg}$, orally) thrice a week. Group IV: animals which were instilled with benzo(a)pyrene (B(a)P) $(50 \mathrm{mg} / \mathrm{kg}$, orally) twice within an interval of 2 weeks. Group V: animals which received Aq.Tc extract as in group II, along with B(a)P after 2 weeks of Aq.Tc administration. Group VI: animals which received AG as in group III along with B(a)P after 2 weeks of AG administration.

Results: As expected, B(a)P treated mice exhibited high tumor incidence and multiplicity with concomitant increase in serum/plasma markers like carcinoembryonic antigen (CEA), circulating tumor DNA (ctDNA), lactate dehydrogenase (LDH) and tumor necrosis factor. However, Aq.Tc and AG supplementation to B(a)P abused animals significantly attenuated these parameters at different stages of cancer, depicting their anti-cancer effects in lung carcinogenesis. Also, treatment of Aq.Tc and AG to tumor bearing mice reduced the degree of histopathological alterations as compared to $\mathrm{B}(\mathrm{a}) \mathrm{P}$ installed mice. The apoptotic index in case of Aq.Tc and AG fed mice treated with $\mathrm{B}(\mathrm{a}) \mathrm{P}$ was higher as compared to only $\mathrm{B}(\mathrm{a}) \mathrm{P}$ treated mice. Further it was observed that Aq.Tc could induce higher degree of apoptosis when compared to AG group, suggesting Aq.Tc as a more effective modulator of tumorigenesis.

Conclusion: Overall, these findings substantiate the chemopreventive potential of Aq.Tc and AG against lung tumorigenesis. Aq.Tc was found to be more effective than AG in modulating the process of lung carcinogenesis as reflected by various observations.
\end{abstract}

Implication for health policy/practice/research/medical education:

Tinospora cordifolia plant and its various bioactive components have wide range of pharmacological properties. Aqueous extract of Tinospora cordifolia stem and arabinogalactan (AG), its bioactive polysaccharide, act as anti-cancer agents and have the potential for preparation of new drugs against lung cancer.

Please cite this paper as: Mohan V, Koul A. Anticancer potential of Tinospora cordifolia and arabinogalactan against benzo(a) pyrene induced pulmonary tumorigenesis: a study in relevance to various biomarkers. J Herbmed Pharmacol. 2018;7(4):225-235. doi: 10.15171/jhp.2018.35.

\section{Introduction}

Lung cancer is the prime cause of cancer mortality and is a growing economic burden worldwide (1). Primary factors that lead to induction of lung cancer include use of tobacco, automobile exhausts, occupational exposure and indoor air pollution (2). Polycyclic aromatic hydrocarbons (PAHs) are the major constituents of these pollutants
(3). One of the most potent PAH, Benzo(a)pyrene $\{\mathrm{B}(\mathrm{a})$ $\mathrm{P}\}$ is known to induce lung cancer in humans as well as experimental animals (4).

In spite of various advancements in lung cancer diagnosis and treatment, survival rates remain low (5). Generally, tumor size and its extent of invasion detected histopathologically (biopsy) is considered to be the gold 
standard for evaluating the disease (6). Since the procedure of biopsy is invasive and could add to the agony of the patient, different serological markers of tumor could be taken into account for specific diagnosis and evaluation of progress of cancer (7). Sensitive and specific diagnostic markers of lung cancer could facilitate the early detection of the cancer lowering the associated mortality rates (8). Various serum markers include circulating tumor DNA (ctDNA), carcinoembryonic antigen (CEA), neuron specific enolase (NSE), carbohydrate antigen 125 (CA125) and squamous cell carcinoma antigen (SCC) (9). These markers when combined with other diagnostic tools could classify tumor into different molecular subtypes and monitor disease relapse and treatment response (10).

Since, there is no magic bullet to combat cancer, lung cancer is no exception to it, never the less, the risk could be reduced by eliminating contact or exposure to putative carcinogens. But this may not be feasible always, considering the quality of air, soil and water in the present scenario. Therefore, it presses the need for adopting other practical measures to control the dreadful disease. The complexity of this hyperproliferative disease necessitates the adoption of secondary prevention as a rational way to control it (11). The use of botanicals in the form of vegetables, fruits and other dietary supplements as chemopreventive agents seem to be relevant (12). Chemoprevention is a reasonable and cost-effective approach to decrease cancer mortality by inhibiting the pre-cancerous events and/or delaying its progression (13). Most of the drugs that are available to combat cancer have shown severe side effects. Synthetic chemopreventive drugs are cytotoxic, immune suppressants and may cause a variety of ill effects in various organs of the body (14). Various drugs that are currently being used are based on folk remedies and subsequent ethnopharmacological studies. There are more than 100 drugs of known structure that are extracted from medicinal plants. As modern medicine came up, people started looking for active components from the crude extract but due to their higher/acute side effects they are not much being used (15). Various medicinal plants have been identified for their anticancer properties and in varied number of ailments $(16,17)$. Tinospora cordifolia is a known medicinal plant having a wide spectrum of pharmacological activity. It is commonly known as 'Guduchi' or 'Amrita' and is considered as an important drug of Indian Systems of Medicine (18). Different parts of this plant including leaves, roots and stem have been widely used for their variety of medicinal properties (19). However, use of stem has been widely reported, so far (20). T. cordifolia is known to exhibit anti-inflammatory and anti-cancer properties in various experimental models (21). There are several experimental reports which document the anticancer potential of aqueous, methanolic as well as ethanolic extracts of $T$. cordifolia in various cancer models
$(22,23)$. One of the active constituents in its polysaccharide fraction is arabinogalactan (AG) (24). Its potent biological activity and immune-enhancing properties have received increased attention as a clinically useful nutraceutical agent (25). AG has several properties which make it an ideal adjunct supplement to be considered in cancer protocols (26).

Aqueous extract of $T$. cordifolia is enriched in the polysaccharide fraction containing AG when compared with other types of extract (27). Many biological activities of $T$. cordifolia have been attributed to its polysaccharide fraction (28). The above mentioned observations warrant further investigations with respect to preparations rich in AG or its use as such active principle.

The polysaccharide fraction of $T$. cordifolia in lung has shown profound anti-metastatic activity against lung cancer cell lines (29). However, not much has been explored about its effect in in vivo lung cancer models and the underlying mechanism involved. Considering this, the present study was designed to assess the effects of aqueous T. cordifolia extract and its bioactive polysaccharide AG in in vivo benzo(a)pyrene induced pulmonary carcinogenesis model.

\section{Material and Methods}

Chemicals and kits

1,1-diphenyl 2-picrylhydrazyl (DPPH), 2,2'-azino-bis(3ethylbenzothiazoline-6-sulphonic acid) (ABTS), Benzo(a) pyrene (B(a)P) and AG (99\% pure) were obtained from Sigma-Aldrich Co. (St. Louis, MO, USA). Rest of the chemicals used were of analytical grade. Terminal deoxynucleotidyl transferase dUTP nick end labelling (TUNEL) assay kit was procured from Trevigen Inc. (Gaithersburg, Maryland, USA). FitAmp ${ }^{\mathrm{TM}}$ Circulating DNA Quantification kit was procured from Epigenetek (Farmingdale, New York, USA).

Preparation of aqueous Tinospora cordifolia stem extract Tinospora cordifolia stems were collected from the Panjab University Botanical Garden after identification by a qualified Botanist. Aqueous powder of T. cordifolia was prepared according to method described by Tiwari et al, with minor modifications (30,31). Dried Aq. Tc powder (500 mg) was reconstituted in $10 \mathrm{~mL}$ of distilled water and was subjected to preliminary screening for the presence of phytoconstituents by standard protocol (32).

Free radical scavenging activity assays

Free radical scavenging activity of Aq.Tc as well as AG was analysed using DPPH (1,1-diphenyl 2-picrylhydrazyl) radical scavenging assay (33) and ABTS radical cation $\left(\mathrm{ABTS}^{+}\right)$assay (34).

Animals and experimental conditions

Male Balb/c mice (25-30 g) were procured from the Central 
Animal House, Panjab University, Chandigarh (Approval no PU/IAEC/S/15/61 Panjab University, Chandigarh). Mice were housed in polypropylene cages bedded with sterilized rice husk and were provided with standard pellet diet (Ashirwad Industries Ltd., Ropar, Punjab, India) and water ad libitum with standard conditions of relative humidity $(50 \%-60 \%)$ and temperature $\left(24 \pm 2^{\circ} \mathrm{C}\right)$. Mice were acclimatized to the experimental conditions for one week after which various treatments were given.

\section{Experimental design}

Mice were randomly segregated into 6 groups ( $n=6-$ 8). Group I animals served as control and received no special treatment. Group II animals were administered aqueous T. cordifolia extract (Aq.Tc) (200 mg/kg, orally) on the alternate days (thrice a week). Group III animals were administered AG $(7.5 \mathrm{mg} / \mathrm{kg}$, orally) on alternate days (thrice a week). Group IV animals were instilled with $\mathrm{B}(\mathrm{a}) \mathrm{P}(50 \mathrm{mg} / \mathrm{kg}$, i.p.) twice, within an interval of two weeks. Group V animals received Aq.Tc extract as in group II, along with $\mathrm{B}(\mathrm{a}) \mathrm{P}$ was installed after 2 weeks of Aq.Tc administration following the same protocol as for group IV. Group VI animals received AG as in group
III along with B(a)P was instilled after 2 weeks of AG administration following the same protocol as in group IV. Changes in body weight, diet and water intake were observed every week in all the groups throughout the treatment period. Dose of Aq.Tc in the present study was standardized according to the available literature $(200 \mathrm{mg}$ / $\mathrm{kg}$ ) (35). Dose of AG was deduced considering the amount of AG (active polysaccharide) present in $200 \mathrm{mg}$ of Aq.Tc which amounted to $7.5 \mathrm{mg} / \mathrm{kg}$ (Figure 1A).

Tumor assessment studies

Tumor statistics

At the end of the treatment period ( 22 weeks), the lung tissue/lung tumors were excised and analyzed for $(a)$ tumor incidence $(b)$ tumor size $(c)$ tumor multiplicity following the protocol of Gupta et al (36).

\section{Histopathological evaluation}

Lung tissue/tumors were excised at the end of 10th and 22nd weeks, fixed in $10 \%$ formaldehyde in phosphate buffer saline ( $\mathrm{pH} 7.4$ ) for Haematoxylin and eosin (H\&E) staining as per the conventional laboratory procedures (37). H\&E stained slides were evaluated under light

(A)

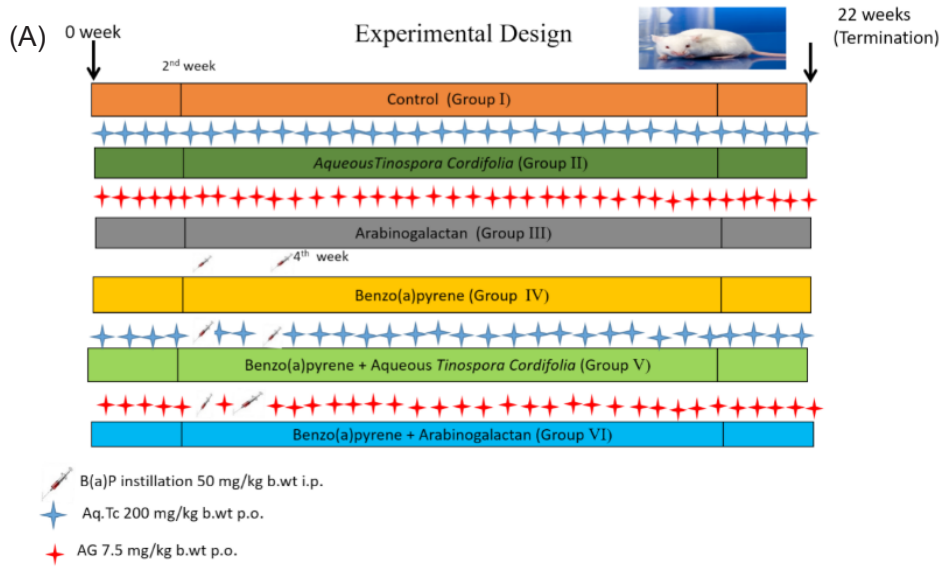

(B) 45

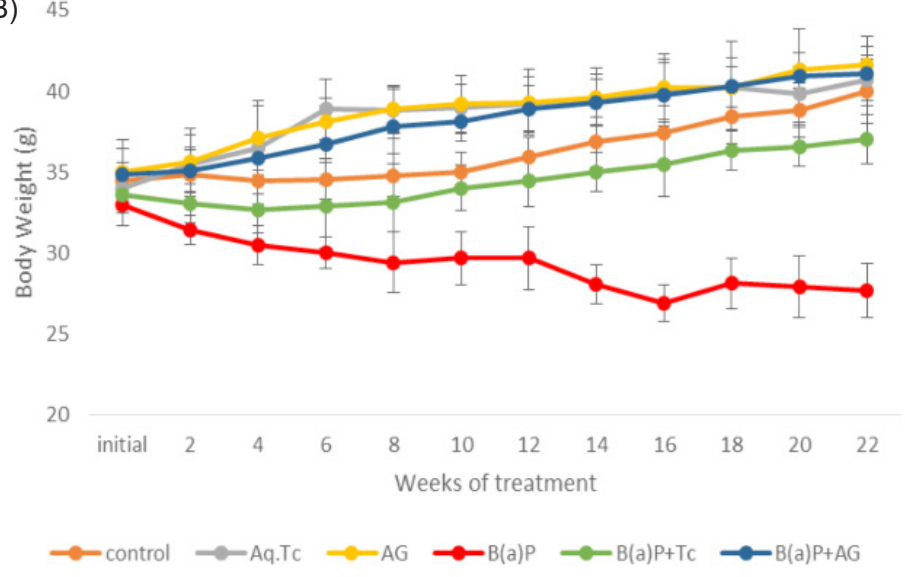

Figure 1. (A) Animal treatment schedule to study the effect of Aq.Tc and AG in B(a)P induced pulmonary carcinogenesis. (B) Alterations in average body weight of the animals during the treatment period. Data were represented as Mean \pm S.D. $(n=6-10)$ 
microscope (LEICA DM 3000).

Tumor markers

Various tumor markers were estimated in the plasma/ serum of mice from different treatment groups. Blood samples from the mice of various treatment groups were collected by retro-orbital puncture. Prior to retro-orbital puncture, a drop of $0.5 \%$ pro-paracaine hydrochloride ophthalmic solution (Sunways Pvt. Ltd. India) was applied to anesthetize the eyes so that pain was reduced.

\section{Carcinoembryonic antigen}

Quantification of tumor marker CEA was estimated in blood serum using the Qayee-Bio Mouse carcinoembryonic antigen ELISA kit. The detection range of the kit lies between $78 \mathrm{pg} / \mathrm{mL}$ to $5000 \mathrm{pg} / \mathrm{mL}$.

\section{Circulating tumor DNA}

Circulating tumor DNA was quantified using the FitAmp ${ }^{\mathrm{TM}}$ Circulating DNA Quantification kit for mouse. The linear detection range of the kit lies between $0.1 \mathrm{ng}$ to $100 \mathrm{ng}(1-1000 \mathrm{ng} / \mathrm{mL})$ in $96-$ well plate assay. DNA was fluorescently quantified at Ex 480-500 and Em 520$550 \mathrm{~nm}$ using a fluorescence microplate reader (Biotek Synergy H1 microplate reader).

\section{Lactate dehydrogenase}

The specific activity of Lactate dehydrogenase (LDH) in blood serum was estimated according to the method described by Bergmeyer and Bernt (38) using molar extinction coefficient $6.22 \mathrm{mM}^{-1} \mathrm{~cm}^{-1}$.

Quantification of tumor necrosis factor-alpha

Quantitative estimation of tumor necrosis factor- $a$ (TNF- $\alpha$ ) in blood serum samples of various treatment groups was carried out by using in vitro enzyme linked immunosorbent assay (ELISA) (Ray Biotech). The minimum detectable dose of mouse TNF- $\alpha$ is $30 \mathrm{pg} / \mathrm{ml}$.

\section{TUNEL assay}

The TUNEL assay was performed on deparaffinised and rehydrated lung sections with the TACS-XL DAB in situ apoptosis detection kit according to the manufacturer's specifications. Apoptotic index was calculated as the percentage of TUNEL (+ve) cells were quantified over the total number of cells in the selected lung tissue section.

\section{Statistical analysis}

The data were represented as mean \pm standard deviation (SD). and analysed by one-way ANOWA followed by LSD post hoc test using the SPSS software package (version 16) for windows (SPSS Inc., Chicago, IL).

\section{Results}

Phytochemical screening

In the present study, preliminary phytochemical analysis of Aq.Tc stem extract showed the presence of alkaloids, phenols, flavonoids, carbohydrates, and proteins. However, steroids were found to be absent in the extract.

Free radical scavenging activity

In DPPH and ABTS free radical scavenging assay Aq.Tc extract exhibited free radical scavenging activity in a concentration dependent manner when compared with other strong antioxidants like BHT and tannic acid (Figure 2A and 2B). It showed a higher antiradical activity with $\mathrm{IC}_{50}$ of $432 \mu \mathrm{g}$ and $49.8 \mu \mathrm{g}$ in DPPH and ABTS assays, respectively. However, AG showed a greater antiradical activity at higher concentrations when compared with Aq.Tc, BHT and tannic acid. The $\mathrm{IC}_{50}$ of $\mathrm{AG}$ was found to be $648 \mu \mathrm{g}$ and $384.17 \mu \mathrm{g}$ in DPPH and ABTS assay, respectively (Table 1 ).

Body status, diet and water intake

Mice in all the experimental groups did not show any significant change in the diet and water consumption throughout the treatment period. A considerable decrease in the body weight of animals in $\mathrm{B}$ (a)P group was observed when compared with their control counterparts. There was no significant difference in the body growth patterns in animals treated with Aq.Tc and AG i.e., Aq.Tc, AG, B(a) $\mathrm{P}+\mathrm{Aq} \cdot \mathrm{Tc}$ and $\mathrm{B}(\mathrm{a}) \mathrm{P}+\mathrm{AG}$ group when compared with control group (Figure 1B).

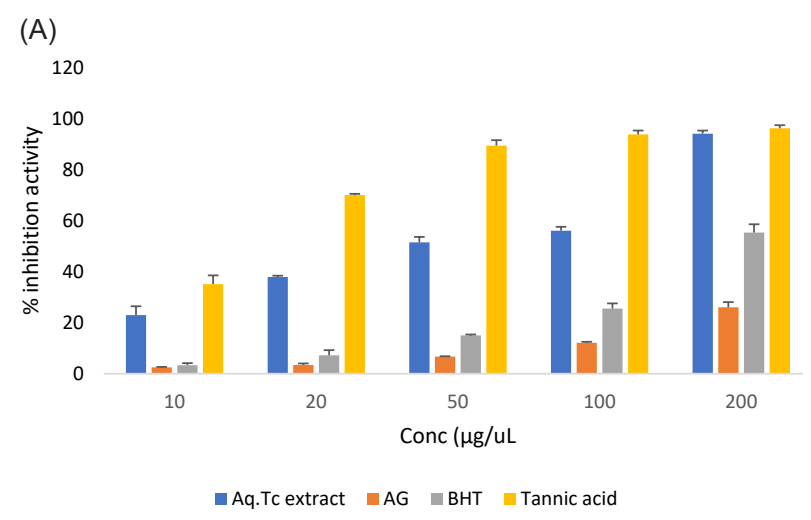

(B)

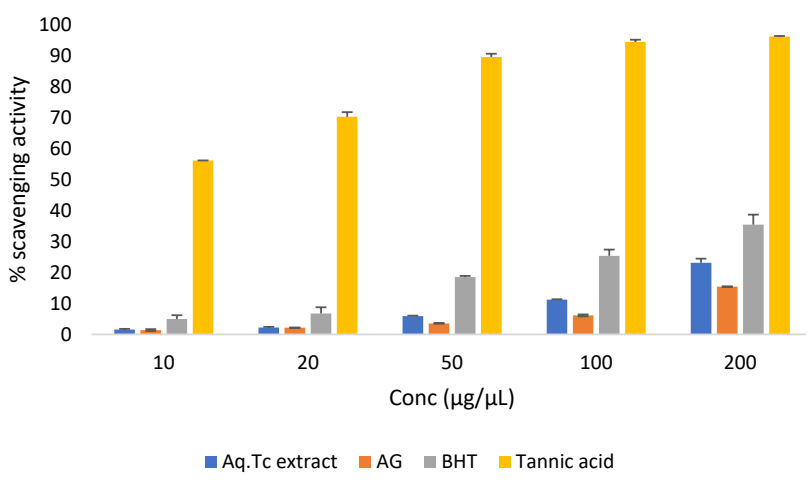

Figure 2. (A) Radical scavenging effects of Aq.Tc. Extract and AG on ABTS radicals. (B) Radical scavenging effects of Aq.Tc. extract and $A G$ on DPPH radicals. Data were represented as mean \pm SD $(n=3)$. 
Table 1. $I_{50}$ values of Aq.Tc. extract, $A G, B H T$ and tannic acid using ABTS and DPPH scavenging activity

\begin{tabular}{lll}
\hline $\begin{array}{l}\text { Extract/ } \\
\text { Compound }\end{array}$ & $\begin{array}{ll}\mathrm{IC}_{50} \text { value }(\mu \mathrm{g} / \mu \mathrm{L}) & \mathrm{IC}_{50} \text { values }(\mu \mathrm{g} / \mu \mathrm{L}) \\
\text { DPPH assay }\end{array}$ \\
\hline Tannic acid & 14.24 & 103.21 \\
BHT & 49.80 & 282.40 \\
Aq.TC & 180.66 & 432.52 \\
AG & 384.17 & 648.50 \\
\hline
\end{tabular}

\section{Morphological changes in lung/lung tumors}

Normal architecture was observed in Aq. Tc and AG treated lung when compared with control animals (Figure 3A). However, in $\mathrm{B}(\mathrm{a}) \mathrm{P}$ challenged mice lung, large number of superficial lesions and hematomas were observed. Prominent tumor nodules around different lobes of lung were also present (Figure 3B). Mice bearing tumors coadministered with Aq.Tc and AG showed a significant reduction in tumor nodules and tumor mass (Figure 3C, $\mathrm{D}, \mathrm{E}$ and $\mathrm{F}$, respectively).

\section{Tumor statistics}

After 22 weeks of the B(a)P treatment, the mice from B(a) $\mathrm{P}, \mathrm{B}(\mathrm{a}) \mathrm{P}+\mathrm{Aq} \cdot \mathrm{Tc}$ and $\mathrm{B}(\mathrm{a}) \mathrm{P}+\mathrm{AG}$ group developed lung tumors, whereas no tumor/lesion was observed in control, Aq.Tc and AG group.

The total number of tumors/lesions formed in various experimental groups and the associated parameters are summarised in Table 2.

\section{Histopathology}

Tenth week of B(a)P treatment showed loss of normal pulmonary architecture and higher number of hyper chromatic nuclei with air space enlargement (Figure 4B). However, in animals from $\mathrm{B}(\mathrm{a}) \mathrm{P}+\mathrm{Aq}$. Tc and $\mathrm{B}(\mathrm{a}) \mathrm{P}+\mathrm{AG}$ groups showed decreased number of hyperchromatic irregular cells in the alveolar wall at 10th week of treatment (Figure 4D-F). Histopathological changes in the pulmonary tissue at 22nd week post instillation of $\mathrm{B}(\mathrm{a})$ $P$ revealed extensive proliferation of alveolar epithelium, large number of eosinophilic macrophages infiltrating the pulmonary parenchyma with more number of hyper chromatic nuclei in the alveolar wall (Figure 5B). Number of hyperproliferative cells in $\mathrm{B}(\mathrm{a}) \mathrm{P}+\mathrm{Aq}$. Tc and $\mathrm{B}(\mathrm{a}) \mathrm{P}+$ $\mathrm{AG}$ group decreased when compared to $\mathrm{B}(\mathrm{a}) \mathrm{P}$ group at
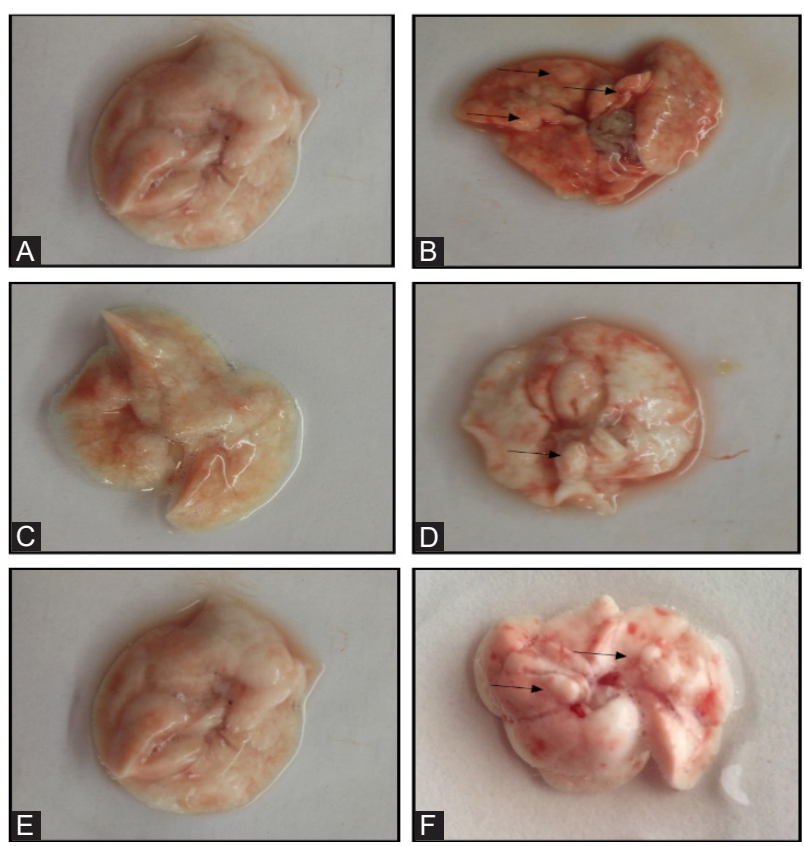

Figure 3. Gross morphology of lungs in mice of different treatment groups.

(A) Control, (B) Pulmonary lesions in $\mathrm{B}(\mathrm{a}) \mathrm{P}$ treated mice, (C), Aq.Tc, (D) B(a)P treated mice co-administered with Aq.Tc. extract, (E) AG, (F) B(a)P treated mice co-administered with AG. (arrow indicates tumor).

22nd week of treatment (Figure 5D-F).

Tumor markers

Carcinoembryonic antigen

Instillation of $\mathrm{B}(\mathrm{a}) \mathrm{P}$ showed a significant $(P \leq 0.001)$ increase in the CEA levels in a time dependent manner when compared with the rest of the groups $(158 \pm 1.36$ to $288 \pm 21.0 \mathrm{pg} / \mathrm{mL})$. However, in $\mathrm{B}(\mathrm{a}) \mathrm{P}+\mathrm{AG}$ group the increase was less intense ( $162 \pm 6.20$ to $228 \pm 2.12 \mathrm{pg} / \mathrm{mL})$. Interestingly, the levels of CEA in $\mathrm{B}(\mathrm{a}) \mathrm{P}+\mathrm{Aq}$. Tc group dropped from $165 \pm 6.20$ to $143 \pm 16.4 \mathrm{pg} / \mathrm{mL}$ (Table 3).

\section{Circulating tumor DNA}

A significant increase in ctDNA levels was observed in $\mathrm{B}(\mathrm{a}) \mathrm{P}$ group at different time intervals when compared with other respective groups $(1.15 \pm 0.012$ to $3.28 \pm 0.140$ $\mathrm{ng} / \mathrm{mL})$. However, Aq.Tc administration to the cancer bearing animals, significantly $(P \leq 0.001)$ lowered the

Table 2. Effect of Aq.Tc and AG on B(a)P induced lung tumorigenesis at end of the treatment period where $(n=6-10)$

\begin{tabular}{lccccc}
\hline Parameters/Groups & Control & Aq.Tc & AG & B(a)P & B(a)P+Aq.Tc \\
\hline Tumor incidence $(\%)$ & - & - & - & $100 \%$ & $66.6 \%$ \\
Tumor multiplicity & - & - & - & $2.45 \pm 0.365$ & $1.22 \pm 0.057 *$ \\
Total no of tumors & - & - & - & 96 & $1.52 \pm 0.125 * *$ \\
Big tumors $(>2 \mathrm{~mm})$ & - & - & - & 73 & 43 \\
Small tumors $(<2 \mathrm{~mm})$ & - & - & - & 13 & 93 \\
\hline
\end{tabular}

Data is expressed as Mean \pm SD and are analysed by Student's $t$ test.

$* P \leq 0.01, * * P<0.05$ with regard to $\mathrm{B}(\mathrm{a}) \mathrm{P}$. 


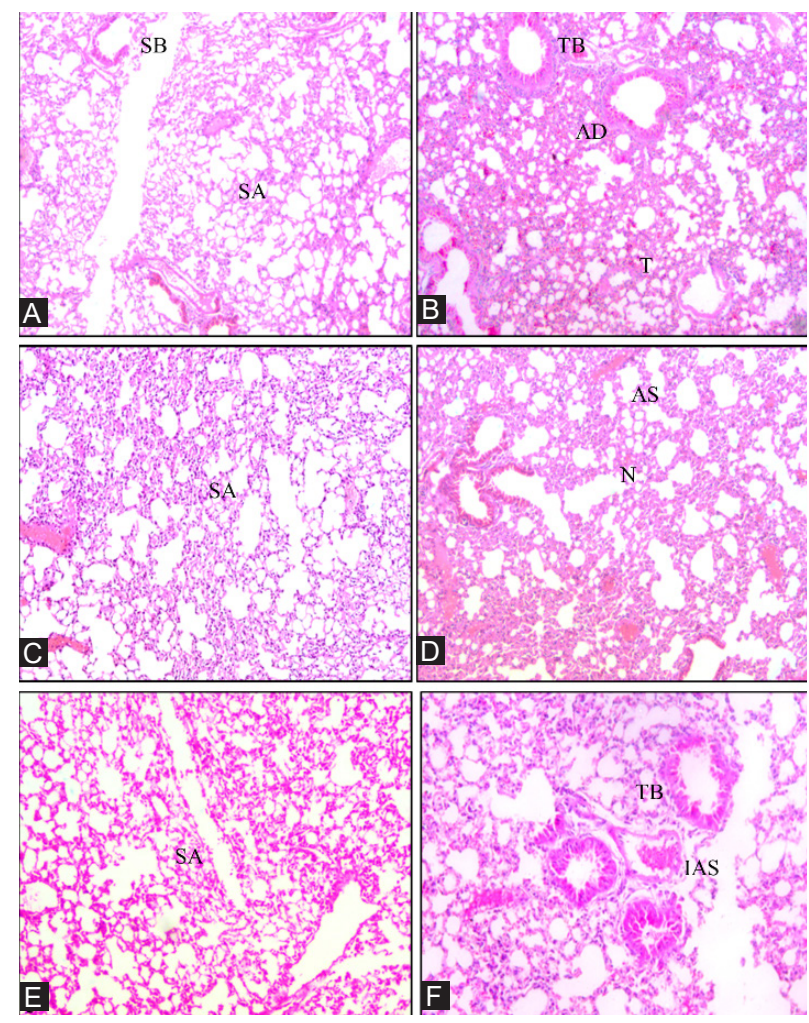

Figure 4. Hematoxylin and eosin stained lung tissue at 10th week of treatment at $200 \mathrm{X}$.

(A). Control mice showing normal histoarchitecture, (B) B(a)P treated mice, (C) Aq.Tc treated mice, (D) B(a)P installed mice co-treated with Aq.Tc, (E) AG treated mice, (F) B(a)P installed mice co-treated with AG. SB; small bronchiole, SA; single squamous epithelium, AW; alveolar wall, AS; alveolar space, AD; Widespread alveolar destruction, $\mathbf{N}$; thinning of alveolar walls, T; thickening of alveolar wall, IAS; increased alveolar sac, TB; thickened bronchiolar epithelium.

levels of ctDNA to their near normal values. Also, the levels of ctDNA were found to significantly $(P \leq 0.001)$ decreased in $\mathrm{B}(\mathrm{a}) \mathrm{P}+\mathrm{AG}$ animals when compared to the $\mathrm{B}(\mathrm{a}) \mathrm{P}$ group (Table 3$)$.

\section{Lactate dehydrogenase}

A significant increase in LDH activity in $\mathrm{B}(\mathrm{a}) \mathrm{P}$ group was observed when compared to various treatment groups $(259 \pm 54.1$ to $628 \pm 16.5 \mathrm{IU} / \mathrm{L})$. However, treatment of Aq.Tc to the cancer bearing animals significantly $(P \leq$ 0.001) restored the levels of LDH to their near normal values. Also, the levels of $\mathrm{LDH}$ were found to significantly $(P \leq 0.001)$ reduced in $\mathrm{B}(\mathrm{a}) \mathrm{P}+\mathrm{AG}$ animals when compared to the $\mathrm{B}(\mathrm{a}) \mathrm{P}$ group (Table 3 ).

\section{Quantification of TNF-alpha}

TNF-alpha levels were significantly increased in $\mathrm{B}(\mathrm{a})$ $\mathrm{P}$ group when compared to control, Tc and AG groups at different time intervals. Whereas, Aq.Tc treatment to cancer bearing animals significantly $(P \leq 0.001)$ restored the level of TNF-alpha to their near normal values. Also, the levels of TNF-alpha significantly decreased $(P \leq 0.001)$
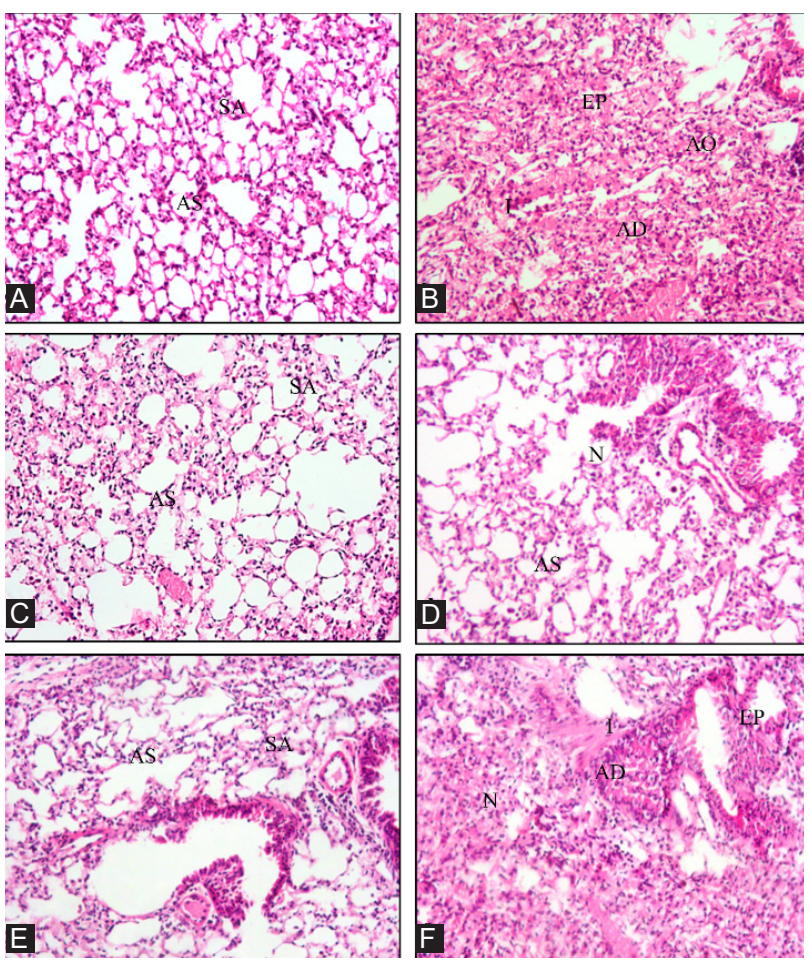

Figure 5. Haematoxylin and Eosin stained lung tissue/lung tumors at $200 \mathrm{X}$.

(A) Control mice showing normal histoarchitecture, (B) B(a)P treated mice, (C) Aq.Tc treated mice, (D) B(a)P induced tumor co-treated with Aq.Tc, (E) AG treated mice, (F) B(a)P induced tumor co-treated with AG. (EP: extensive proliferation of alveolar epithelium and presence of hyperchromatic nuclei in the alveolar wall; SB; small bronchiole, SA; single squamous epithelium, AW; alveolar wall, AS; alveolar space, AD; Widespread alveolar destruction, $\mathbf{N}$; thinning of alveolar walls, $\mathbf{T}$; thickening of alveolar wall, IAS; increased alveolar sac, TB; thickened bronchiolar epithelium, I; Inflammatory cellular infiltrations.

in $\mathrm{B}(\mathrm{a}) \mathrm{P}+\mathrm{AG}$ animals when compared to the $\mathrm{B}(\mathrm{a}) \mathrm{P}$ group (Table 3).

\section{TUNEL assay}

A significant increase in the apoptotic index in $\mathrm{B}(\mathrm{a}) \mathrm{P}+$ Aq.Tc group was observed when compared with rest of the four groups i.e., control, AG, B(a)P and Aq.Tc. There was a significant increase in extent of apoptosis in $\mathrm{B}(\mathrm{a}) \mathrm{P}+\mathrm{AG}$ group but much less than the $\mathrm{B}(\mathrm{a}) \mathrm{P}+$ Aq.Tc group (Figure $6 \mathrm{~A}, \mathrm{~B})$.

\section{Discussion}

Lung and the associated respiratory system is the prime target of the inhaled contaminated air which include pollutants and carcinogens like $\mathrm{B}(\mathrm{a}) \mathrm{P}$ that have been established as important etiological agents in causation of lung cancers (39). Majority of lung cancers are diagnosed at late stages when the options for treatment are mostly palliative (40). Management of lung cancer requires monitoring of the tumor burden to determine the response to treatment and therefore, improved biomarkers are 
Table 3. Effect of Aq.Tc and AG on various blood tumor markers at different time intervals during B(a)P induced lung tumorigenesis

\begin{tabular}{|c|c|c|c|c|c|c|c|}
\hline Parameters/Groups & Weeks & Control & Aq.Tc & AG & $B(a) P$ & $B(a) P+A q \cdot T c$ & $B(a) P+A G$ \\
\hline \multirow[t]{3}{*}{ CEA $(\mathrm{pg} / \mathrm{ml})$} & 0 & $160.5 \pm 1.56$ & $160.3 \pm 9.30$ & $164.5 \pm 6.82$ & $159.5 \pm 1.36$ & $162.2 \pm 10.7$ & $162.9 \pm 6.20$ \\
\hline & 10 & $164.8 \pm 4.54$ & $146.8 \pm 12.9$ & $168.1 \pm 11.73$ & $251.1 \pm 8.64 a_{1} b_{1} c_{1}$ & $165.5 \pm 11.6 \mathrm{~d}_{1}$ & $\begin{array}{l}205.3 \pm 11.0 \\
c_{3} e_{3}\end{array}$ \\
\hline & 22 & $164.2 \pm 5.49$ & $176.0 \pm 15.4$ & $174 \pm 6.57$ & $\begin{array}{l}288.3 \pm 21.0 \\
a_{3} b_{1} c_{1}\end{array}$ & $\begin{array}{l}143.1 \pm 16.4 \\
d_{1}\end{array}$ & $\begin{array}{l}228.7 \pm 2.12 \\
b_{2} d_{2}\end{array}$ \\
\hline \multirow[t]{3}{*}{ ctDNA (ng/ml) } & 0 & $1.28 \pm 0.012$ & $1.11 \pm 0.013$ & $1.21 \pm 0.010$ & $1.15 \pm 0.012$ & $1.17 \pm 0.010$ & $1.19 \pm 0.020$ \\
\hline & 10 & $1.29 \pm 0.015$ & $1.27 \pm 0.062$ & $1.34 \pm 0.219$ & $\begin{array}{l}2.95 \pm 0.060 \\
a_{1} b_{1} c_{1}\end{array}$ & $\begin{array}{l}1.65 \pm 0.189 \\
a_{1} b_{1} c_{1} d_{1}\end{array}$ & $\begin{array}{l}2.37 \pm 0.210 \\
a_{1} b_{1} c_{1} d_{2}\end{array}$ \\
\hline & 22 & $1.41 \pm 0.010$ & $1.30 \pm 0.010$ & $1.31 \pm 0.005$ & $\begin{array}{l}3.28 \pm 0.140 \\
a_{1} b_{1} c_{1}\end{array}$ & $\begin{array}{l}2.33 \pm 0.100 \\
d_{1}\end{array}$ & $\begin{array}{l}2.52 \pm 0.136 \\
a_{1} b_{1} c_{1} d_{2} e_{2}\end{array}$ \\
\hline \multirow[t]{3}{*}{ LDH(IU/L) } & 0 & $249.5 \pm 58.8$ & $304.0 \pm 33.9$ & $278.1 \pm 45.6$ & $259.1 \pm 54.1$ & $259.9 \pm 53.0$ & $252.1 \pm 51.9$ \\
\hline & 10 & $233.9 \pm 63.8$ & $311.8 \pm 46.7$ & $278.1 \pm 50.7$ & $\begin{array}{l}688.7 \pm 50.7 \\
a_{1} b_{1} c_{1}\end{array}$ & $\begin{array}{l}465.2 \pm 62.5 \\
a_{2} b_{2} c_{2} d_{2}\end{array}$ & $\begin{array}{l}491.2 \pm 56.2 \\
a_{2} b_{2} c_{2} d_{2}\end{array}$ \\
\hline & 22 & $246.9 \pm 67.2$ & $218.3 \pm 48.6$ & $155.4 \pm 41.2$ & $\begin{array}{l}628.9 \pm 16.5 \\
a_{2} b_{2} c_{1}\end{array}$ & $\begin{array}{l}293.7 \pm 16.2 \\
d_{3}\end{array}$ & $\begin{array}{l}343.3 \pm 27.0 \\
d_{3}\end{array}$ \\
\hline \multirow[t]{3}{*}{ TNF- $\alpha(p g / m l)$} & 0 & $44.6 \pm 0.01$ & $46.1 \pm 0.01$ & $48.2 \pm 2.99$ & $45.4 \pm 2.30$ & $44.0 \pm 1.70$ & $46.4 \pm 2.83$ \\
\hline & 10 & $46.0 \pm 2.35$ & $46.3 \pm 2.71$ & $43.6 \pm 2.02$ & $\begin{array}{l}59.6 \pm 2.91 \\
a_{1} b_{1} c_{1}\end{array}$ & $\begin{array}{l}49.6 \pm 2.04 \\
c_{1} d_{1}\end{array}$ & $\begin{array}{l}49.4 \pm 1.55 \\
c_{2} d_{1}\end{array}$ \\
\hline & 22 & $44.6 \pm 2.64$ & $46.2 \pm 2.71$ & $48.2 \pm 2.11$ & $\begin{array}{l}66.9 \pm 4.16 \\
a_{1} b_{1} c_{1}\end{array}$ & $\begin{array}{l}49.8 \pm 0.20 \\
d_{1}\end{array}$ & $\begin{array}{l}51.2 \pm 1.44 \\
a_{3} d_{1}\end{array}$ \\
\hline
\end{tabular}

Data is expressed as Mean \pm SD $(n=6-8)$. Data is analysed using one-way ANOVA followed by post-hoc test. $a_{1} P \leq 0.001, a_{2} P \leq 0.01, a_{3} P \leq 0.05$ significant with respect to control group; $\mathrm{b}_{1} P \leq 0.001, \mathrm{~b}_{2} P \leq 0.01$ significant with respect to Tc group; $\mathrm{c}_{1} P \leq 0.001, \mathrm{c}_{2} P \leq 0.01, \mathrm{c}_{3} P \leq 0.05$ significant with respect to Arb group; $\mathrm{d}_{1} P \leq 0.001, \mathrm{~d}_{2} P \leq 0.01$, significant with respect to $\mathrm{B}(\mathrm{a}) \mathrm{P}$ group; $\mathrm{e}_{2} P \leq 0.01, \mathrm{e}_{3} P \leq 0.05$ significant with respect to $\mathrm{B}(\mathrm{a}) \mathrm{P}+\mathrm{Tc}$ group.

needed (41). The present study was aimed to evaluate the efficacy of Aq.Tc extract and its active component, AG, in $\mathrm{B}(\mathrm{a}) \mathrm{P}$ induced lung tumorigenesis and to demonstrate the effect on various plasma/serum markers at different stages of pulmonary carcinogenesis.

To assess the chemopreventive efficacy of Aq.Tc/AG in in vivo system various parameters were studied in $\mathrm{Balb} / \mathrm{c}$ mice pulmonary tumor model. The considerable weight loss observed in tumor bearing mice could be related to cancer cachexia, anorexia or malabsorption, which resulted in wasting of skeletal muscle and adipose tissue (42). Several studies have shown similar observations of decrease in body weight of animals following administration of B(a) $P$ (43). However, Aq.Tc and AG seem to prevent this alteration in body weight of lung tumor bearing mice. Chemopreventive response of Aq.Tc and AG administered animals challenged with $\mathrm{B}(\mathrm{a}) \mathrm{P}$ induced carcinogenesis was monitored on the basis of tumor incidence, multiplicity, size and gross morphology. All these parameters serve as a valuable reference to study the development of carcinogenesis in in vivo studies. Aq.Tc was successful in reducing the extent of carcinogenesis as depicted by different parameters like tumor morphology, multiplicity and incidence when compared to $\mathrm{B}(\mathrm{a}) \mathrm{P}$ group. Mean number of large and small tumors was also observed to be significantly altered in Aq.Tc treated animals. However, in $\mathrm{B}(\mathrm{a}) \mathrm{P}+\mathrm{AG}$ mice less reduction in mean number of small tumors was observed but the number of large tumors varied, significantly. Earlier studies also supported our observation depicting that various plant extracts were successful in reducing lung adenoma incidence and multiplicity induced by $\mathrm{B}(\mathrm{a}) \mathrm{P}$ in mice. To the best of our knowledge no reports are available of chemopreventive effects of Aq.Tc extract and AG in in vivo lung tumor model.

Mode of cell death can be a useful parameter to assess the severity of the cancer (44). Dysregulation of apoptosis is pivotal to tumorigenesis and the development of most cancers (45). Aq.Tc treated animals bearing tumors revealed enhanced apoptosis in comparison to the $\mathrm{B}(\mathrm{a})$ $\mathrm{P}$ treated mice bearing pulmonary tumors. Increase in apoptotic index may also be responsible for the decrease in the size of the tumors in the $\mathrm{B}(\mathrm{a}) \mathrm{P}+\mathrm{Aq}$. Tc group. The induction of apoptosis by Aq.Tc extract has already been documented in the literature as a potential candidate in therapy to glioblastomas (46). Pure active component AG of $T$. cordifolia was found to be less effective in inducing apoptosis in lung tumor bearing mice. Our lab also reported the induction of apoptosis by using different plant extracts in cancer models (47).

Pro-inflammatory cytokines such as TNF- $\alpha$ are the major molecular players involved in inflammation to cancer axis. As a representative inflammatory cytokine with pleiotropic functions, TNF- $\alpha$ plays a dual role in carcinogenesis (48). In the present study, the gradual increased levels of TNF- $\alpha$ at 10th and 22nd week of treatment in lung cancer bearing animals may be due to pronounced inflammatory response and increased cell 

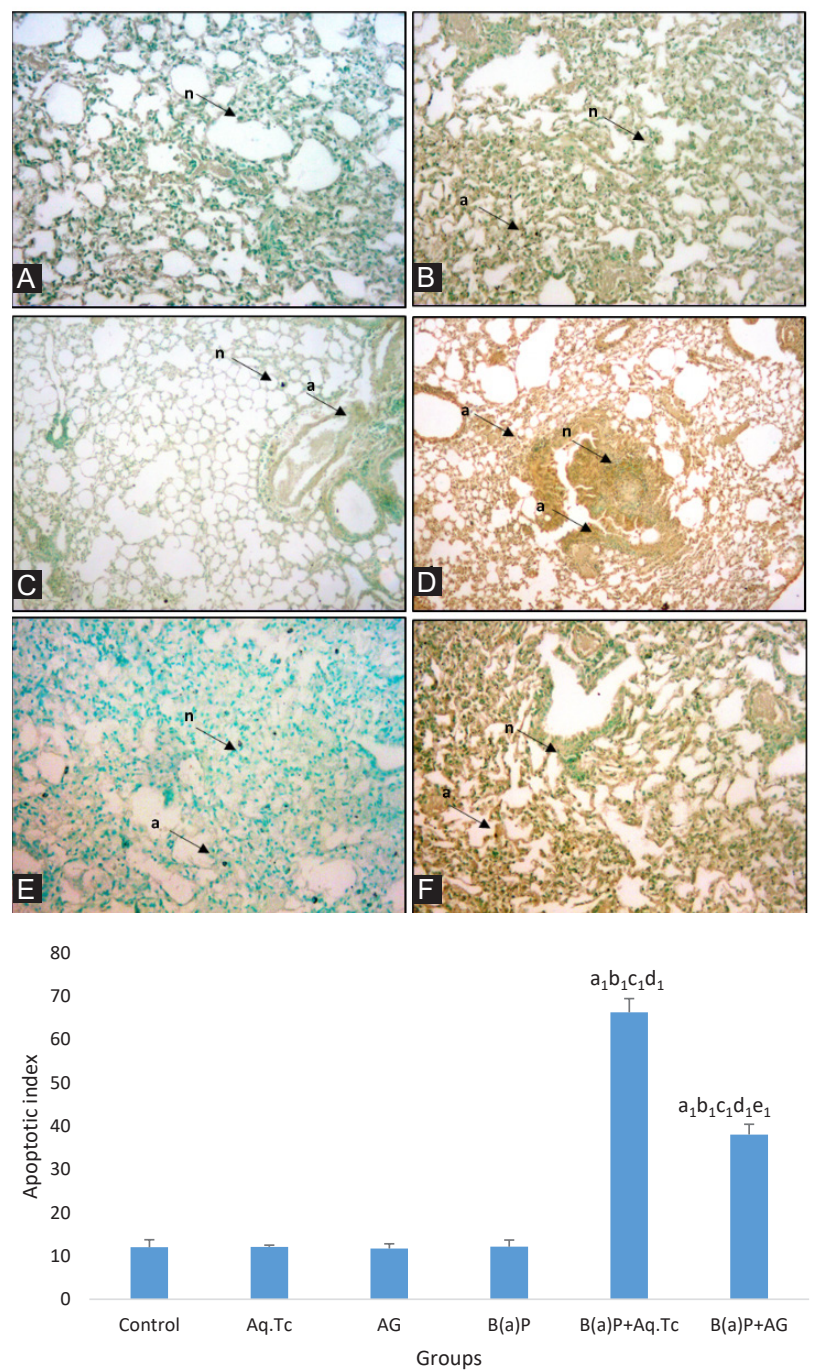

Figure 6. (A) TUNEL assay performed in paraffin embedded lung/ tumor tissue sections at 200X.

a. Control, b. Benzo(a)pyrene, c. Tinospora cordifolia extract, d. Benzo(a)pyrene+ Tinospora cordifolia extract group, e. AG treated, f. Benzo(a)pyrene+ AG treated group.

Green stained cells represent non-apoptotic cells (n), brown stained cells represent apoptotic cells (a). (B) Attenuation in apoptotic index of $\mathrm{B}(\mathrm{a}) \mathrm{P}$ induced lung tumors and its chemoprevention by Aq.Tc and AG.

Data is represented as mean $\pm S D(n=5)$ and analysed by oneway ANOVA followed by the post hoc test. Statistical significance and symbols: $\mathrm{a}_{1} P \leq 0.001$ w.rt control group; $\mathrm{b}_{1} P \leq 0.001$ w.rt $\mathrm{B}(\mathrm{a})$ $P$ group; $c_{1} P \leq 0.001$ w.rt Aq. Tc group.

death by $\mathrm{B}(\mathrm{a}) \mathrm{P}$ administration. Also, there is increasing evidence that TNF- $\alpha$ is mainly produced by cancers and act as an endogenous tumor promoter (49). Studies have shown that $\mathrm{B}(\mathrm{a}) \mathrm{P}$ administration promotes the increase of TNF- $\alpha$ levels in pulmonary tumor bearing mice (50). At 10th week of Aq.Tc and AG treatment to cancer bearing animals significantly downregulated the levels of TNF- $\alpha$ to near normal values. The results of the present study are in collaboration with several other reports which suggested that $T$. cordifolia administration to cancer bearing mice downregulated the levels of TNF-a suggesting the immunomodulating activity of $T$. cordifolia extract (51). Surprisingly, there was no change in TNF-a levels after 10th week of the treatment protocol in $\mathrm{B}(\mathrm{a}) \mathrm{P}+\mathrm{Aq}$. Tc and $\mathrm{B}(\mathrm{a}) \mathrm{P}+\mathrm{AG}$ treated groups which could be because of higher apoptotic index found in both these groups.

$\mathrm{LDH}$ is a sensitive marker for solid tumors and enhanced activity of this enzyme has been reported in serum of various lung tumor patients (52). Serum LDH was observed to be increased at the promotion stage (10th week) followed by progression stage (22nd week) of tumorigenesis in $\mathrm{B}(\mathrm{a}) \mathrm{P}$ treated mice which could be due to the increased glycolysis in cancerous conditions or the cellular leakage of these enzymes in circulation. Our results are in agreement with earlier findings which depicted that $\mathrm{B}(\mathrm{a}) \mathrm{P}$ administration increased the levels of $\mathrm{LDH}$ in cancer bearing animals (53). A subsequent decrease in LDH activity on treatment with Aq.Tc aids in the protection against abnormal cell growth by changing the permeability of membrane or by affecting the cellular growth of the tumor. Our lab also reported, reduction of pulmonary and serum levels of LDH upon administration of Aloe vera gel extract to cigarette smoke exposed mice (54). In the present study, AG administration was less efficient in normalising the LDH activity when compared to the Aq.Tc extract. AG was found to be less effective in protecting the membrane permeability and cellular proliferation of cells damaged by $\mathrm{B}(\mathrm{a}) \mathrm{P}$ insult.

CEA is one of the extensively studied tumor markers which has also shown prognostic value and has been found to overexpress on the cell surface of malignant epithelialtype (55). It is considered as a sensitive tumor marker for diagnosis, prognosis, and therapy monitoring of lung cancer (56). Gradual increase in serum CEA levels (10th and 22nd week) in B(a)P installed animals was observed which could be associated with increase in tumor growth and cellular proliferation rate. Available literature also suggests that CEA levels increase concomitantly in lung tumor bearing mice (53). Reduction in levels of CEA in Aq.tc and AG treated animals could be due to decrease in tumor growth that reveal the anti-tumor effects of these compounds. Reduction in levels of CEA was more pronounced in $\mathrm{B}(\mathrm{a}) \mathrm{P}+\mathrm{Aq}$. Tc than $\mathrm{B}(\mathrm{a}) \mathrm{P}+\mathrm{AG}$ group which shows Aq.Tc extract has more potent anticancer activity. An earlier finding suggested that thymoquinone, which is the main active constituent of black seed and essential oil, reduced the serum CEA levels in benzo(a) pyrene induced lung cancer (57).

Evaluation of plasma ctDNA is a promising diagnostic and prognostic marker which circumvents the complications associated with use of invasive techniques used for biological sampling (58). In the present study, a spike in ctDNA concentration was prominent at 10th week of the treatment with $\mathrm{B}(\mathrm{a}) \mathrm{P}$ administration which could be because of the increase in necrosis of tumor cells, or release of the intact cells into the bloodstream and their 
lysis. Further increase in ctDNA in lung tumor bearing animals at 22nd week of the treatment could be because of the severe progression of the tumor cells or the increase of micro metastatic cells in the blood, which can also shed their DNA into the blood circulation (59). A significant drop in ctDNA level was visible in Aq.Tc treated animals which almost reached the level observed in normal healthy animals. Also, in animals treated with AG, the drop in ctDNA level was not as striking as compared to Aq.Tc treated animals bearing pulmonary tumors. This decrease in DNA level is either because plasma DNA is released at lower rates or is due to rapid degrade. ctDNA release in blood stream could be also correlated to the mode of cell death as its concentration depends whether the cell is undergoing apoptotic cell death or necrotic cell death (60). Histopathological findings were also in concordance with altered levels of CEA, LDH, ctDNA and TNF- $\alpha$, which showed profound increase in their levels at different stages of carcinogenesis.

Conclusion: Our findings suggest that a concaminant increase in various tumor markers like CEA, ctDNA, $\mathrm{LDH}$ and TNF-alpha at different stages of carcinogenesis correlates well with the histopathological changes observed at early and late stages of $\mathrm{B}(\mathrm{a}) \mathrm{P}$ induced lung cancer. Aq.Tc successfully improved the various blood markers and decreased the severity of the disease as revealed by histopathological and other parameters. Although AG modulated the above mentioned parameters but Aq.Tc seemed to be much more effective as a chemopreventive agent. The histopathological findings in the present study are in concordance with the biochemical observations and are suggestive of the fact that Aq.Tc and AG have a potential as chemopreventive agents in pulmonary carcinogenesis.

\section{Acknowledgement}

We express our heartfelt gratitude to the Department of Biophysics, Panjab University, Chandigarh, India for providing the necessary facilities and assistance to carry out this research work.

\section{Authors' contributions}

The idea of the study, its design and interpretation to come to a conclusion were done by AK and VM. However, the experimental procedures were done by VM under the guidance of AK. Both contribute in preparation of the manuscript and agreed publication of the final proof.

\section{Conflict of interests}

Authors declare no conflict of interests.

\section{Ethical considerations}

Ethical issues have been observed by the authors. The experimental animal studies were approved by the ethical committee, Panjab University, Chandigarh, India
(Approval no PU/IAEC/S/15/61 Panjab University, Chandigarh) and were conducted adhering to the Indian National Science Academy Guidelines for the use and care of experimental studies.

\section{Funding/Support}

This research was financially supported by the University Grants Commission (UGC) BSR fellowship, New Delhi (India).

\section{References}

1. Siegel RL, Miller KD, Jemal A. Cancer statistics, 2016. CA Cancer J Clin. 2016;66(1):7-30. doi: 10.3322/caac.21332.

2. Dela Cruz CS, Tanoue LT, Matthay RA. Lung cancer: epidemiology, etiology, and prevention. Clin Chest Med. 2011;32(4):605-44. doi: 10.1016/j.ccm.2011.09.001.

3. Abdel-Shafy HI, Mansour MSM. A review on polycyclic aromatic hydrocarbons: Source, environmental impact, effect on human health and remediation. Egypt J Petrol 2016;25(1):107-23. doi: 10.1016/j.ejpe.2015.03.011.

4. Kasala ER, Bodduluru LN, Barua CC, Sriram CS, Gogoi R. Benzo(a)pyrene induced lung cancer: Role of dietary phytochemicals in chemoprevention. Pharmacol Rep. 2015;67(5):996-1009. doi: 10.1016/j.pharep.2015.03.004.

5. Shi X, Liu H, Song Y. Pollutional haze as a potential cause of lung cancer. J Thorac Dis. 2015;7(10):E412-7. doi: 10.3978/j.issn.2072-1439.2015.05.04.

6. Bourgioti C, Chatoupis K, Moulopoulos LA. Current imaging strategies for the evaluation of uterine cervical cancer. World J Radiol. 2016;8(4):342-54. doi: 10.4329/wjr. v8.i4.342.

7. Liu L, Teng J, Zhang L, Cong P, Yao Y, Sun G, et al. The Combination of the Tumor Markers Suggests the Histological Diagnosis of Lung Cancer. Biomed Res Int. 2017;2017:2013989. doi: 10.1155/2017/2013989.

8. Xiang D, Zhang B, Doll D, Shen K, Kloecker G, Freter C. Lung cancer screening: from imaging to biomarker. Biomark Res. 2013;1(1):4. doi: 10.1186/2050-7771-1-4.

9. Yu D, Du K, Liu T, Chen G. Prognostic value of tumor markers, NSE, CA125 and SCC, in operable NSCLC Patients. Int J Mol Sci. 2013;14(6):11145-56. doi: 10.3390/ ijms140611145.

10. Mehta S, Shelling A, Muthukaruppan A, Lasham A, Blenkiron C, Laking G, et al. Predictive and prognostic molecular markers for cancer medicine. Ther Adv Med Oncol. 2010;2(2):125-48. doi: 10.1177/1758834009360519.

11. Arora N, Koul A. A 'complex solution' to a 'complex' problem: tackling the complexity of cancer with botanicals. Eur J Cancer Prev. 2014;23(6):568-78. doi: 10.1097/ cej.0000000000000045.

12. Sofowora A, Ogunbodede E, Onayade A. The role and place of medicinal plants in the strategies for disease prevention. Afr J Tradit Complement Altern Med. 2013;10(5):210-29.

13. Maresso KC, Tsai KY, Brown PH, Szabo E, Lippman S, Hawk ET. Molecular cancer prevention: Current status and future directions. CA Cancer J Clin. 2015;65(5):345-83. doi: $10.3322 /$ caac. 21287 .

14. Safarzadeh E, Sandoghchian Shotorbani S, Baradaran B. Herbal medicine as inducers of apoptosis in cancer 
treatment. Adv Pharm Bull. 2014;4(Suppl 1):421-7. doi: 10.5681/apb.2014.062.

15. Koul A, Gangar SC, Sandhir V. Pitfalls in journey from traditional to modern medicine. Nat Prod Radiance. 2005;4(1):6-13.

16. Greenwell M, Rahman PK. Medicinal Plants: Their Use in Anticancer Treatment. Int J Pharm Sci Res. 2015;6(10):410312. doi: 10.13040/ijpsr.0975-8232.6(10).4103-12.

17. Prakash O, Kumar A, Kumar P, Ajeet A. Anticancer Potential of Plants and Natural Products: A Review. Am J Pharmacol Sci. 2013;1(6):104-15. doi: 10.12691/ajps-1-6-1.

18. Sinha K, Mishra NP, Singh J, Khanuja SPS. Tinospora cordifolia (Guduchi), a reservoir plant for therapeutic applications: a review. Indian J Tradit Knowl. 2004;3(3):25770 .

19. Bahadur S, Mukherjee PK, Milan Ahmmed SK, Kar A, Harwansh RK, Pandit S. Metabolism-mediated interaction potential of standardized extract of Tinospora cordifolia through rat and human liver microsomes. Indian J Pharmacol. 2016;48(5):576-81. doi: 10.4103/02537613.190758.

20. Saha S, Ghosh S. Tinospora cordifolia: one plant, many roles. Anc Sci Life. 2012;31(4):151-9. doi: 10.4103/02577941.107344.

21. Patni K. The amazing pharmacological properties of Tinospora cordifolia - A short review. Int J Ayu Pharm Chem. 2015;4(2):105-29.

22. Handique PJ. In vitro propagation and medicinal attributes of Tinospora cordifolia: A review. Austin J Biotechnol Bioeng. 2014;1(5):5.

23. Jagetia GC, Rao SK. Evaluation of the antineoplastic activity of guduchi (Tinospora cordifolia) in Ehrlich ascites carcinoma bearing mice. Biol Pharm Bull. 2006;29(3):4606.

24. Uppuluri S, Ali SL, Nirmala T, Santhi M, Sipai Babu SD. A Review on Tinospora cordifolia. International Journal of Current Pharmaceutical Review and Research. 2013;4(2):61-8.

25. Dion C, Chappuis E, Ripoll C. Does larch arabinogalactan enhance immune function? A review of mechanistic and clinical trials. Nutr Metab (Lond). 2016;13:28. doi: 10.1186/ s12986-016-0086-X.

26. Shakhtshneider TP, Kuznetsova SA, Zamay AS, Zamay TN, Spivak EA, Mikhailenko MA, et al. New composites of betulin esters with arabinogalactan as highly potent anti-cancer agents. Nat Prod Res. 2016;30(12):1382-7. doi: 10.1080/14786419.2015.1060591.

27. Chaudhari S, Shaikh N. Gaduchi-The Best Ayurvedic Herb. The Pharma Innovation Journal. 2013;2(4):97-102.

28. Nair PK, Rodriguez S, Ramachandran R, Alamo A, Melnick SJ, Escalon E, et al. Immune stimulating properties of a novel polysaccharide from the medicinal plant Tinospora cordifolia. Int Immunopharmacol. 2004;4(13):1645-59. doi: 10.1016/j.intimp.2004.07.024.

29. Leyon PV, Kuttan G. Effect of Tinospora cordifolia on the cytokine profile of angiogenesis-induced animals. Int Immunopharmacol. 2004;4(13):1569-75. doi: 10.1016/j. intimp.2004.06.015.

30. Tiwari P, Kumar B, Kumar M, Kaur M, Debnath J, Sharma P. Comparative Anthelmintic Activity of Aqueous and
Ethanolic Stem Extract of Tinospora cordifolia. Int J Drug Dev Res. 2011;3(1):70-83.

31. Mishra R, Kaur G. Aqueous ethanolic extract of Tinospora cordifolia as a potential candidate for differentiation based therapy of glioblastomas. PLoS One. 2013;8(10):e78764. doi: 10.1371/journal.pone.0078764.

32. Kokate CK. Pratical Pharmacognosy. New Delhi: Vallabh Prakan; 1994.

33. Sudha G, Priya MS, Rajan-Babu IS, Vadivukkarasi S. In vitro free radical scavenging activity of raw pepino fruit (Solanum muricatum Aiton). Int J Curr Pharm Res. 2011;3(2):137-40.

34. Re R, Pellegrini N, Proteggente A, Pannala A, Yang M, RiceEvans C. Antioxidant activity applying an improved ABTS radical cation decolorization assay. Free Radic Biol Med. 1999;26(9-10):1231-7.

35. Mathew S, Kuttan G. Immunomodulatory and antitumour activities of Tinospora cordifolia. Fitoterapia. 1999;70(1):3543. doi: 10.1016/S0367-326X(98)00017-3.

36. Gupta P, Bansal MP, Koul A. Evaluating the effect of lycopene from Lycopersicum esculentum on apoptosis during NDEA induced hepatocarcinogenesis. Biochem Biophys Res Commun. 2013;434(3):479-85. doi: 10.1016/j. bbrc.2013.03.099.

37. Humanson GL. Animal tissue techniques. 2nd ed. San Fransisco, USA: W.H Freeman; 1961.

38. Bergmeyer HU, Bernt E. Lactate-dehydrogenase, UVassay with pyruvate and NADH. In: Bergmeyer HU, ed. Methods of Enzymatic Analysis. New York: Academic Press; 1974;2:574-9.

39. Field RW, Withers BL. Occupational and environmental causes of lung cancer. Clin Chest Med. 2012;33(4):681-703. doi: 10.1016/j.ccm.2012.07.001.

40. Farbicka P, Nowicki A. Palliative care in patients with lung cancer. Contemp Oncol (Pozn). 2013;17(3):238-45. doi: 10.5114/wo.2013.35033.

41. Dawson SJ, Tsui DW, Murtaza M, Biggs H, Rueda OM, Chin SF, et al. Analysis of circulating tumor DNA to monitor metastatic breast cancer. N Engl J Med. 2013;368(13):1199209. doi: 10.1056/NEJMoa1213261.

42. Aoyagi T, Terracina KP, Raza A, Matsubara H, Takabe K. Cancer cachexia, mechanism and treatment. World J Gastrointest Oncol. 2015;7(4):17-29. doi: 10.4251/wjgo. v7.i4.17.

43. Anandakumar P, Kamaraj S, Ramakrishnan G, Jagan S, Devaki T. Chemopreventive task of capsaicin against benzo(a)pyrene-induced lung cancer in Swiss albino mice. Basic Clin Pharmacol Toxicol. 2009;104(5):360-5. doi: 10.1111/j.1742-7843.2009.00387.x.

44. Fulda S, Gorman AM, Hori O, Samali A. Cellular stress responses: cell survival and cell death. Int J Cell Biol. 2010;2010:214074. doi: 10.1155/2010/214074.

45. Ravichandran N, Suresh G, Ramesh B, Manikandan R, Choi YW, Vijaiyan Siva G. Fisetin modulates mitochondrial enzymes and apoptotic signals in benzo(a)pyrene-induced lung cancer. Mol Cell Biochem. 2014;390(1-2):225-34. doi: 10.1007/s11010-014-1973-y.

46. Pendse VK, Dadhich AP, Mathur PN, Bal MS, Madan BR. Anti-inflammatory immunosuppressive and sme related pharmacological actions of the water extract of Neem 
Giloe (Tinospora cordifolia): A preliminary report. Ind J Pharmacol. 1977;9:221-4.

47. Koul A, Mohan V, Bharati S. Azadirachta indica mitigates DMBA-induced hepatotoxicity: A biochemical and radiometric study. Indian J Biochem Biophys. 2014;51:3745 .

48. Landskron G, De la Fuente M, Thuwajit P, Thuwajit C, Hermoso MA. Chronic inflammation and cytokines in the tumor microenvironment. J Immunol Res. 2014;2014:149185. doi: 10.1155/2014/149185.

49. Wang X, Lin Y. Tumor necrosis factor and cancer, buddies or foes? Acta Pharmacol Sin. 2008;29(11):1275-88. doi: 10.1111/j.1745-7254.2008.00889.x.

50. Anandakumar P, Kamaraj S, Jagan S, Ramakrishnan G, Asokkumar S, Naveenkumar C, et al. Capsaicin inhibits benzo(a)pyrene-induced lung carcinogenesis in an in vivo mouse model. Inflamm Res. 2012;61(11):1169-75. doi: 10.1007/s00011-012-0511-1.

51. Naveenkumar C, Raghunandhakumar S, Asokkumar S, Devaki T. Baicalein abrogates reactive oxygen species (ROS)-mediated mitochondrial dysfunction during experimental pulmonary carcinogenesis in vivo. Basic Clin Pharmacol Toxicol. 2013;112(4):270-81. doi: 10.1111/ bcpt. 12025 .

52. Radhakrishnan VK, Ravikumar V, Shivashangari KS, Kamaraj S, Devaki T. Chemopreventive Role of Lycopene and D-arginine in Benzo (a) Pyrene Induced Lung Cancer with Reference to Lipid Peroxidation, Antioxidant System and Tumor Marker Enzymes. Int J Cancer Res. 2006;2(3):224-33. doi: 10.3923/ijcr.2006.224.233.

53. Kamaraj S, Ramakrishnan G, Anandakumar P, Jagan S, Devaki T. Antioxidant and anticancer efficacy of hesperidin in benzo(a)pyrene induced lung carcinogenesis in mice. Invest New Drugs. 2009;27(3):214-22. doi: 10.1007/s10637-
008-9159-7.

54. Koul A, Bala S, Yasmeen, Arora N. Aloe vera affects changes induced in pulmonary tissue of mice caused by cigarette smoke inhalation. Environ Toxicol. 2015;30(9):999-1013. doi: $10.1002 /$ tox.21973.

55. Veronesi G, Pelosi G, Sonzogni A, Leon ME, D’Aiuto M, Gasparri R et al. Tumour CEA as predictor of better outcome in squamous cell carcinoma of the lung. Lung Cancer.2005; 48:233-240, doi:10.1016/j.lung can.2004.10.018.

56. Shao Y, Sun X, He Y, Liu C, Liu H. Elevated Levels of Serum Tumor Markers CEA and CA15-3 Are Prognostic Parameters for Different Molecular Subtypes of Breast Cancer. PLoS One. 2015;10(7):e0133830. doi: 10.1371/ journal.pone.0133830.

57. Hussein SA, Abdel-Aal SA, Amin A, Khalaf HA. Caspase-3, Bcl-2, p53, CYP1A1 and COX-2 as a potential target in chemoprevention of Benzo (a) pyrene-induced lung carcinogenesis in mice: Role of thymoquinone. Int J Chem Nat Sci. 2016;4(3):430-41.

58. Pathak AK, Bhutani M, Kumar S, Mohan A, Guleria R. Circulating cell-free DNA in plasma/serum of lung cancer patients as a potential screening and prognostic tool. Clin Chem. 2006;52(10):1833-42. doi: 10.1373/ clinchem.2005.062893.

59. Gold B, Cankovic M, Furtado LV, Meier F, Gocke CD. Do circulating tumor cells, exosomes, and circulating tumor nucleic acids have clinical utility? A report of the association for molecular pathology. J Mol Diagn. 2015;17(3):209-24. doi: 10.1016/j.jmoldx.2015.02.001.

60. Iba T, Hashiguchi N, Nagaoka I, Tabe Y, Murai M. Neutrophil cell death in response to infection and its relation to coagulation. J Intensive Care. 2013;1(1):13. doi: 10.1186/2052-0492-1-13. 